\title{
Causes of Academic Procrastination Among High School Pupils with Learning Disabilities in Ilorin, Kwara State, Nigeria
}

\author{
Olaniyi Bojuwoye \\ Kwara State University \\ Nigeria
}

\begin{abstract}
With time pressure and increased use of technology people nowadays tend to put off things or delay intended courses of action. The behaviour tendency to voluntarily postpone, delay or put off a task or decision is described as procrastination which has serious negative outcomes. The purpose of the study was to ascertain the causes of academic procrastination by pupils with learning disabilities in the secondary schools of Ilorin metropolis, Kwara State, Nigeria. Structured questionnaire consisting of statements about different factors responsible for procrastination was used to gather relevant information from respondents. Results of data analysis revealed that indecision, time management, lack of motivation, fear of failure, poor organizational skills, high stress, poor coping strategies and peer influence, in that descending order of importance or priority, were considered by participants as causes for their academic procrastination. Results also revealed gender differences in the causes of academic procrastination considered by the respondents. The results have implications for the creation of knowledge and awareness of factors responsible for academic procrastination among secondary school pupils in order to intervene in the negative consequences to the well-being of the pupils.
\end{abstract}

\section{Introduction}

The behaviour tendency to put off or defer actions or tasks to a later time or even infinity is described as procrastination [1]. The phenomenon is also described as the voluntary delay or postponement of some important tasks or the frequent failure to do what needs be done in order to reach goals [2]. Thus a procrastinator is someone who knows what to do, how to do it, tries to do it, but still does not do it [3].

Procrastination takes place in almost every-day behaviours [1]. It has cognitive, affective and behavioural components and manifests in different forms including as in academic, decisional, neurotic or compulsive procrastination [4], but the most common form is academic procrastination [5]. Academic procrastination is a common behaviour problem among school and university students [4].

Within academic environment, full of events and activities competing for students' time and attention, academic procrastination is widespread as students are required to meet deadlines [1]. Academic procrastination is often described as "student syndrome" as many students often begin to engage themselves in a task just before deadline [6]. According to Ozer, Demir and Ferrari [7], procrastination affects 46 to $95 \%$ of students. Gargari, Sabouri and Norzad [4] also assert that an estimated rate of problematic academic procrastination among undergraduate students is 70 to $95 \%$.

Academic procrastination is considered to be the pervasive and permanent desire on the part of a student to postpone academic activities [7]. It is the delaying of academic work that must be completed or the failure to complete an academic task within the expected time frame [10]. Deferring study to the night just before examination and the accompanied anxiety and haste are the most obvious and familiar instance of academic procrastination [8].

Procrastination has received many empirical attentions especially within the field of psychology. Research findings have generally linked procrastination to personal behavioural factors such as lack of motivation, deficiencies in self-regulation, external locus of control, perfectionism, disorganization and poor time management [9]. Lack of motivation is commonly blamed for procrastination especially when the task is unpleasant and less exciting [7]. Lack of motivation also is the result when a task's goals are unclear or underestimated. Moreover, when a student is confronted with a boring academic assignment or an assignment high in difficulty level, the student may not be motivated to start or complete the assignment.

Self-regulation failure, the inability or failure to control one's mood and emotions is often cited as a cause of procrastination [11]. According to Ferrari and Tice [12], the behaviour tendency of not being able to manage one's emotions and reactions is the real cause of procrastination. You's [10] assertion is that procrastinators delay or participate less in learning activities because of failure to accomplish self-regulation. Gargari, Sabouri and Norzad [4] are of the view that failure to accomplish self-regulation is due to lower ability to resist social temptations especially when distant academic prizes are undervalued. Wang [11] argues further that contends that when an unpleasant task meets a person who is 
high in impulsivity and low in self-discipline procrastination is the result.

Deficient time management and poor study skills have also come under the radar as causes of procrastination [8]. You [10] sees a link between procrastination and poor time management especially with students having problems with everyday academic tasks such as studying for tests and examinations or completing assignments. It is further contented that among behaviour variables of procrastination linked to poor time management are a lack of proper planning, inability to concentrate on work, fear and anxiety related to failure and negative beliefs about one's capabilities.

However, Ferrari and Tice [12] assert that chronic procrastination is not only a time management issue but also indecision as difficulty with making decisions is a behaviour that correlates positively with procrastination. Ferrari and Tice [12] explain further that procrastination is not just delaying or waiting to gather resources and information before making decisions but rather it is a decision not to act. It is that gap between intention and action, that is, between knowing what you ought to do and not being able to bring your-self to doing it. Major factor responsible for indecision is self-efficacy, that is, beliefs in one's capabilities to carry out the actions needed to succeed in a task. In academic settings, self-efficacy is a strong predictor of performance and found to have an inverse relationship with procrastination $[12,16]$.

External control or evaluation is another cause of academic procrastination [11]. Some people tend to rebel against or resist being controlled by some other people. For instance, a student may rebel against his or her parents for being forced to choose a course or an academic programme leading to a specific career which the student may not want. The student may, therefore, be involved in procrastination behaviour by not completing assignments or tasks in that course of study for the career because it has been imposed on the student.

Other inter-related causes of academic procrastination include difficulty level of task, distractions or noisy place of study and attributions of results and consequences of tasks to luck or fate [4].

\section{The Study}

Academic procrastination is a common phenomenon among all students in school. Students with learning disabilities are, therefore, no exception. They may even be more affected especially when the peculiar problems associated with their disabilities are not being properly addressed or not addressed at all. Numerous negative academic outcomes are associated with academic procrastination including missing deadlines for submitting assignments, delaying studying for tests and examinations and obtaining low grades [4]. Academic procrastination is also associated with negative psychological and physiological outcomes such as depression, low selfesteem, anxiety, guilt and stress [7]. Also, poor preparation for tests and examinations, resulting in increased test anxiety and lower grades are but a few of the negative consequences of academic procrastination [12].

Since procrastination is found to seriously impact academic performance of students, there is, therefore, the need to provide appropriate interventions to combat the damaging consequences of procrastination. First and foremost, there is need to recognize or acknowledge the causes of procrastination in their different forms, and to promptly take them under control, before this bad habit damages students' career and pride, or destroys their interpersonal relationships and overall wellbeing. Finding out what causes or are responsible for procrastination, therefore, becomes more apparent. The present study, therefore, had this as its main problem focus and the following specific purposes of the study:

1. To ascertain what high school students with learning disabilities in Ilorin metropolis, Kwara State, Nigeria consider as the causes of academic procrastination;

2. To explore gender differences in the causes of academic procrastination as identified by the subjects of this study?

By carrying out this study the researchers also intended to contribute to literature on procrastination in the academic context in Nigeria.

\section{Methodology}

\subsection{Subjects}

The population for the study included all students with learning disabilities in the high schools in Ilorin metropolis, Kwara State, Nigeria. The study sample comprised one hundred and fifty students with learning disabilities (80 males and 70 females). A multi-stage sampling technique was employed for drawing the sale for the study. The first stage involved random sampling to select the schools where learners with learning disabilities were enrolled. The second stage involved purposively selecting students with learning disabilities, identified by their teachers, to participate in the study. The process also involved providing information about the study, explaining the conditions for participation and obtaining the informed consents of those finally selected to participate in the study. 


\subsection{Instrument}

As revealed by the literature, most procrastination studies used self-report questionnaires to assess behavioural tendencies causing procrastination either in academic tasks or in daily tasks [10]. In line with this practice a self-report questionnaire titled "Causes of Academic Procrastination Questionnaire" was developed for this study. The structured questionnaire had two sections - one for collecting demographic information including gender and other relevant data about the participants. The second section contained statements on different causes or reasons for academic procrastination. The causes of procrastination were generated from the literature include Lack of Motivation, Lack of Skills to Complete Academic Task, Fear of Failure, Fear of Success, Indecision or Difficulty to Make decision, Rebellion and resistance to external Control and Poor Self-Regulation

For ease of response to the questionnaire adequate explanations were included in the statement of each cause or reason for procrastination. The responses to the questionnaire were coded on a 4-point Likert-type scale to indicate the respondents' degrees of their agreement with the questionnaire statements (Strongly Disagree $=1$, Disagree= 2, Agree= 3, Strongly Agree= 4).

\subsection{Method of Data Analysis}

Each participant's response score on each cause of or reason for procrastination presented on the questionnaire was found. Total response score on each item of the questionnaire, for all respondents or each subgroup of respondents, was also found. The mean response score for all respondents or each subgroup of respondents was calculated to indicate the degrees of agreement to the statements of causes of procrastination as presented on the questionnaire.

\section{Results}

Table 1 below displays information regarding the suggested causes of academic procrastination as presented on the questionnaire and the mean response scores indicating the degrees of agreement with the suggested causes or reasons for procrastination, by all and subgroups of respondents.

According to the information presented on the table, all the mean response scores by the respondents are above average (2) and clustered around the score of 3 to indicate that the respondents' degrees of agreements with the causes of procrastination were above average. This is an indication that the respondents of this study agreed with the causes of procrastination as presented to them on the questionnaire.

Table 1. Suggested causes of academic procrastination by respondents' mean response scores to indicate their degrees of agreement to the causes of procrastination

\begin{tabular}{|c|l|c|c|c|}
\hline S/N & Reasons for or Causes of Procrastination & \multicolumn{3}{|c|}{ Response Mean Scores } \\
\cline { 3 - 5 } & & $\begin{array}{l}\text { All } \\
\text { Participants }\end{array}$ & $\begin{array}{l}\text { Male } \\
\text { Participants }\end{array}$ & $\begin{array}{l}\text { Female } \\
\text { Participants }\end{array}$ \\
\hline 1 & $\begin{array}{l}\text { Lack of Motivation (due to unpleasant, boring or less } \\
\text { exciting task, unclear or underestimating task goals }\end{array}$ & 3.18 & 3.23 & 3.13 \\
\hline 2 & $\begin{array}{l}\text { Lack of Skills to Complete Academic } \\
\text { Tasks/Assignments (poor self-efficacy, self- } \\
\text { handicapping or underestimating one's capacity to } \\
\text { complete task }\end{array}$ & 3.16 & 2.94 & 3.38 \\
\hline 3 & Poor Time Management & 3.29 & 3.20 & 3.37 \\
\hline 4 & $\begin{array}{l}\text { Fear of failure (I don't want to end up failing even after } \\
\text { giving my best or because of limited time and really have } \\
\text { not tried) }\end{array}$ & 3.14 & 2.91 & 3.36 \\
\hline 5 & $\begin{array}{l}\text { Or fear of success (fear that if task is done well next time } \\
\text { even more might be expected of you or that succeeding } \\
\text { may place one in spot light when you prefer the } \\
\text { background) }\end{array}$ & 2.86 & 2.84 & 2.88 \\
\hline 6 & $\begin{array}{l}\text { Lack of interest (or too ambiguous tasks } \\
\text { Indecision (Difficulty or finding it so hard to make } \\
\text { decisions }\end{array}$ & 3.34 & 3.40 & 3.28 \\
\hline 8 & $\begin{array}{l}\text { Rebellion or Resistance (feeling as if tasks are being } \\
\text { imposed from outside) }\end{array}$ & 2.90 & 2.93 & 2.87 \\
\hline 9 & $\begin{array}{l}\text { Poor Self-regulation (waiting for the right mood, } \\
\text { impulsivity, distractions) }\end{array}$ & 3.03 & 3.03 & 3,03 \\
\hline 10 & Peer Pressure Influences & 3.07 & 3.13 & 3.00 \\
\hline
\end{tabular}


The response scores to the items on the questionnaire indicate different priorities or importance attached to the causes of procrastination by the respondents. Thus in terms of rank order of the importance or priority attached to the causes of procrastination by the respondents the rank order by all respondents indicated Indecision (3.34), Poor Time Management (3.29), Lack of Interest (3.28), Lack of Motivation (3.18), Lack of Skills(3.16), Fear of Failure(3.14), Peer Pressure Influence(3.07), Poor Self-Regulation (3.03), Rebellion and Resistance (2.90) and Fear of Success (2.86) in that descending order. The results indicate that Indecision, as a causal factor responsible for academic procrastination, was rated most highly above other causes by the respondents of this study. Fear of Success was rated as the least likely causes of procrastination.

Results of data analysis revealed gender differences. Male respondents' degrees of agreement, in terms of their mean response scores to the questionnaire statements, indicate Lack of Interest (3.56), Indecision (3.40), Lack of Motivation (3.23), Poor Time Management (3.20), Peer Pressure Influence (3.13), Poor Self-Regulation (3.03), Lack of Skills (2.94), Rebellion and Resistance (2.93), Fear of Failure (2.91) and Fear of Success (2.84) in that descending order. The results indicate that the male respondents of this study placed high priority to Lack of Interest as a cause of procrastination than other factors presented to them on the questionnaire. Male respondents also rated Fear of Success as the least likely cause of academic procrastination.

On the other hand, the female respondents, in terms of their mean response scores (and hence their degrees of agreement), rated Lack of Skills (3.38), Poor Time Management (3.37), Fear of Failure (3.36), Indecision (3.28), Lack of Motivation (3.13), Poor Self-Regulation (3.03), Lack of Interest (3.00), Peer Pressure Influence (3.00), Fear of Success (2.88) and Rebellion and Resistance (2.87) in the descending order as causes of academic procrastination. The female respondents placed the highest priority on Lack of Skills to accomplish task as cause of procrastination unlike their male counterparts who gave the highest priority to Lack of Interest.

\section{Discussion}

Many people struggle with procrastination on a daily basis. Many times, people seem not encouraged or motivated to undertake a task or an activity because of myriad of excuses, habits, thoughts, and fears. These behaviour tendencies involve processes which are inter-connected or intertwined. This could be an explanation for the closeness in the mean response scores or the degrees of agreement to the questionnaire statements by the participants of this study. The participants could have perceived the behaviour tendencies responsible as the causes of procrastination to be inter-related or overlapped with one another. This finding is consistent with Jaffe's [2] contention that many behaviour processes that fall under the domain of executive functioning and are associated with procrastination overlap.

Although the participants of the study endorsed all the factors presented to them on the questionnaire as causes of academic procrastination they, however, assigned different priorities or importance to the causes. Thus, the participants rated Indecision, Poor Time Management, Lack of Interest, Lack of Motivation, Lack of Skills, Fear of Failure, Peer Pressure Influence, Poor Self-Regulation, Rebellion and Resistance and Fear of Success in that descending order of degrees of agreement, priority or importance.

Assigning the highest priority to indecision as a cause of procrastination by the participants of this study may not be unconnected with Ozer, Demir and Ferrari's [7] explanation that some people find it so hard to make decision because they wait for others to make the decisions for them. This may be true in a patriarchal society, like in Nigeria, where the young defer decisions to authority figure like parents or teachers. Moreover Gargari, Sabouri and Norzad [4] also note that some people intentionally and unreasonably postpone making decisions because of the uncertainty of the consequences. According to Ferrari and Tice [12], although it is very helpful and useful to gather information to make an informed decision, but often the anxiety around information needed for decision and uncertainty about the outcome of the decision often result in indecision, Not knowing what will eventuate from daily decisions and actions has a tendency to hold people back from taking decision [10].

Literature also suggests that indecision, avoidance and postponing of decision are also related to other behaviour tendencies associated with procrastination which have also been endorsed by the participants of this study. These behaviour tendencies include feeling inadequate or poor academic self-efficacy, lack of confidence, lack of interest or low self-esteem as well as lack of skills or resources. In terms of academic self-efficacy belief, the research results revealed that the tendency for people to postpone decreases when students believe that they are capable of completing or accomplishing the task increases [13].

The participants' choice of Poor Time Management as the second most important cause of procrastination is consistent with Gargari, Sabouri and Norzad's [4] study findings that poor time management may be blamed for procrastination when students are experiencing workload challenges. Van Eerde [13] earlier identified three different types of behaviours associated with poor time management that often facilitate procrastination. The first type of behaviour is associated with task performance. That is, the procrastinator may not be able to meet deadlines or if deadlines are met the work may not be 
of best quality due to time constraints or inadequate time to complete the task. When a certain task is avoided, the distraction created to do so may not cause the avoided task to disappear completely from the procrastinator's mind, and it may resurface frequently causing internal negative consequences [11]. Uncontrolled thinking about the avoided task is continuously produced, causing anxiety and in turn causing the task not to be performed or performed poorly.

The second type of behaviour associated with poor time management resulting in procrastination is related to extra-role behaviour. Here the task goals may be avoided while personal goals are used as distractors. According priority to personal goals instead of the goal of the task is also implicated in the fear of failure as behaviour tendency causing procrastination [14]. The third type of behaviour is related to social interaction whereby procrastination may affect other people as well, like having to wait or having to constantly remind the procrastinator of deadlines.

According to Ferrari and Tice [9] a huge part of procrastination is not poor time management but rather it is poor self-regulation. Steel [15] also contends that procrastinators delay or participate less in learning activities because of a failure in selfregulation. It is further contended that the characteristics or level of regulation skills of procrastinators and non-procrastinators are different. Self-regulated learners have a wide range of cognitive strategies and are able to choose effective ones for their learning [16]. Self-regulated learners utilize metacognitive skills and possessed adaptive motivation and attitudes responding to a variety of academic context [10].

Other causes of procrastination endorsed by the participants of this study which are also consistent with findings in the literature include personality traits such as lack of motivation, self-handicapping behaviours [9], fear of failure, lack of interests and rebellion or resistance [12].

This study also found gender differences in causes of procrastination which is also consistent with the findings in the literature. As observed by Van Eerde [13], male students are slightly more likely to procrastinate than female students. Steel [15] also found procrastination more common in males than females. The study found that male students rated the causes of procrastination higher than female students across more causes as presented on the questionnaire, and this is consistent with the study finding by Steel [15]. Similar relationships have been found across genders for procrastination and test anxiety and other behavioural variables in other studies [3].

\section{Conclusion}

A number of problems in students' school life prevent them from accomplishing their educational responsibilities satisfactorily. One of these problems is academic procrastination, a behaviour tendency involving avoiding, delaying or postponing academic duties such as preparing for exams and delaying homework assignments sometimes or constantly. Academic procrastination in whatever forms causes students failure, academic unhappiness, stress and low life satisfaction. In order for the students to succeed in school and later in life it is necessary to find solution to the problem of academic procrastination. In order to intervene and proffer solution that would enable students to break their academic procrastination behaviours there is need for significant and objective information related to awareness and understanding of the makeups of academic procrastination. In this connection, this study was designed to find out the different causes of academic procrastination especially among young adolescent high school pupils with learning disabilities in Ilorin, Kwara State, Nigeria. The study found different descriptive variables of behaviour tendencies that are related to the causes of academic procrastination including indecision, poor time management, lack of interest, lack of motivation, poor self-efficacy, poor selfregulation skills and fear of failure among others. The one remaining element that is now missing in the process of intervening in the problems of academic procrastination behaviours of students is the act of making use of the information that is now known to implement interventions to reduce the negative consequences of academic procrastination.

\section{References}

[1] R. Gafni and N. Geri. Time management: Procrastination tendency in individual and collaborative tasks. Inter-disciplinary Journal of Information, Knowledge and Management. 2010,5, 115-124.

[2] Eric Jaffe, "Why Wait? The Science Behind Procrastination," Observer Margazine, April 2013, published by the Association of Psychological Science

[3] B.A. Popoola. A study of the relationship between procrastinatory behaviour and academic performance of undergraduate students in a Nigerian university. Afr Symp Onile J Educ Res Netw 2005. Available from: http://africanresearch.org/africansymposium/archives/TAS 5.1/ TAS5.1.pdf\#page $=60$

[4] R. B. Gargari, H. Sabouri and F. Noezad. Academic procrastination: The relationship between causal attribution styles and behavioural postponement. Iran Journal of Behavioural Science, 2011, 5(2), 76-82 
[5] B. Jowkar and M. A. Delavarpur. Relationship between procrastination snd goal orientation. In Journal of New Education Ideas, 2006; 3, 61-80.

[6] D. Ariely and K. Wertenbroch. Procrastination deadlines, and performance. Self-control by precommitment. Psychological Science, 2002, 13(3), 219-234. [7] B. U. Ozer, A. Demir and J. R/ Ferrari. Exploring academic procrastination among Turkish students: Possibe gender differences in prevalence and reasons. Journal of Social Psychology, 2009, 149(2), 241-257

[8] L. J. Solomon and E. D. Rothblum. Academic procrastination: Frequency and cognitive-behavioural correlates Journal of Counselling Psychology, 31(4), 503 509

[9] D. A. Ackerman and B. L. Gross. My instructor made me do it: Task characteristics of procrastination. Journal of Marketing education, 2005,27(5), 5 - 13.

[10] J. W. You. The relationship among academic procrastination, self-regulated learning, fear, academic selfefficacy and perceived academic control in e-learning. The Journal of educational Information and Media, 2012, 18(3), 249-271

[11] A. Y. Wang and M. H. Newlin. Predictors of webstudent performance: The role of self-efficacy and reasons for taking an on-line class Computers in human Behavior, 2012, 18(2),151-163.

[12] J.R. Ferrari and D. M. Tice. Procrastination as a selfhandicap for men and women: A task-avoidance strategy in a laboratory setting. Journal of Research in Personality, 2000, 34(1), 73-83.

[13] W. Van Eerde. Procrastination at work and time management training. Journal of Psychology, 2003, 137, 421-434.

[14] D. Ariely and K. Wertenbroch. Procrastination deadlines, and performance. Self-control by precommitment. Psychological Science, 2002, 13(3), 219-234.

[15] P. Steel. The nature of procrastination: A meta-analytic and theoretical review of quintessential self-regulatory failure. Psychol Bull, 2007, 133, 65-94

[16] C. A.Wolters. Understanding procrastination from a self-regulated learning perspective. Journal of Educational Psychology, 2003, 95(1), 179-187 